\title{
Morphologic and immunophenotypical features distinguishing Merkel cell polyomavirus-positive and negative Merkel cell carcinoma
}

\author{
Thibault Kervarrec $\mathbb{B}^{1,2,3} \cdot$ Anne Tallet ${ }^{4}$ - Elodie Miquelestorena-Standley $\mathbb{D}^{1} \cdot$ Roland Houben $\mathbb{D}^{3} \cdot$ David Schrama $^{3}$. \\ Thilo Gambichler $^{5}$ - Patricia Berthon ${ }^{2}$ - Yannick Le Corre ${ }^{6}$ Ewa Hainaut-Wierzbicka ${ }^{7}$. Francois Aubin ${ }^{8}$. \\ Guido Bens $^{9} \cdot$ Flore Tabareau-Delalande $^{10} \cdot$ Nathalie Beneton $^{11} \cdot$ Gaëlle Fromont $^{12}$ • Flavie Arbion ${ }^{12}$. \\ Emmanuelle Leteurtre $^{13} \cdot$ Michael Herfs $^{14} \cdot$ Antoine Touzé $^{2} \cdot$ Mahtab Samimi $^{2,15} \cdot$ Serge Guyétant ${ }^{1,2}$
}

Received: 9 January 2019 / Revised: 6 May 2019 / Accepted: 7 May 2019 / Published online: 14 June 2019

(c) United States \& Canadian Academy of Pathology 2019

\begin{abstract}
In 2008, Feng et al. identified Merkel cell polyomavirus integration as the primary oncogenic event in $~ 80 \%$ of Merkel cell carcinoma cases. The remaining virus-negative Merkel cell carcinoma cases associated with a high mutational load are most likely caused by UV radiation. The current study aimed to compare the morphological and immunohistochemical features of 80 virus-positive and 21 virus-negative Merkel cell carcinoma cases. Microscopic evaluation revealed that elongated nuclei - similar to the spindle-shape variant of small cell lung cancer-were less frequent in Merkel cell polyomavirus-positive Merkel cell carcinoma compared to the virus-negative subset $(p=0.005)$. Moreover, virus-negative cases more frequently displayed a "large-cell neuroendocrine carcinoma" phenotype with larger cell size $(p=0.0026)$, abundant cytoplasm $(p=$ $\left.4 \times 10^{-7}\right)$ and prominent nucleoli $(p=0.002)$. Analysis of immunohistochemical data revealed frequent positivity for thyroid transcription factor 1 and cytokeratin 7, either absence or overexpression of p53, as well as frequent lack of neurofilament expression in virus-negative cases. By contrast, cytokeratin 8, 18 and 20 and a CD99 with a dot pattern as well as high EMA expression were identified as characteristic features of virus-positive Merkel cell carcinoma. In particular, the CD99 dot-like expression pattern was strongly associated with presence of the Merkel cell polyomavirus in Merkel cell carcinoma (sensitivity $=81 \%$, specificity $=90 \%$, positive likelihood ratio $=8.08$ ). To conclude, virus-positive and -negative Merkel cell carcinoma are characterized by distinct morphological and immunohistochemical features, which implies a significant difference in tumor biology and behavior. Importantly, we identified the CD99 staining pattern as a marker indicating the virus status of this skin cancer.
\end{abstract}

These authors contributed equally: A. Tallet, E. MiquelestorenaStandley

These authors jointly supervised this work: M. Samimi, S. Guyétant

Institutional review board: The local Ethics Committee in Human Research of Tours (France) approved the study (no. ID RCB2009A01056-51)

Supplementary information The online version of this article (https:// doi.org/10.1038/s41379-019-0288-7) contains supplementary material, which is available to authorized users.

Thibault Kervarrec

thibaultkervarrec@yahoo.fr

Extended author information available on the last page of the article

\section{Introduction}

Merkel cell carcinoma is a rare and aggressive neuroendocrine carcinoma of the skin with a 5-year overall survival rate of $40 \%$ [1]. The two main risk factor are immunosuppression [2] and sun exposure [1]. Whereas the incidence is still low, with 0.7 cases per 100,000 person-years in the United States in 2013, a dramatic increase of $95 \%$ was observed between 2000 and 2013, and a further rise in incidence has been predicted [3].

In 2008, Feng et al. identified a polyomavirus which they found integrated in the genome of Merkel cell carcinoma cells and accordingly named it Merkel cell polyomavirus (MCPyV) [4]. Currently, integration of this virus and the expression of viral oncoproteins named $\mathrm{T}$ antigens are established as the primary oncogenic events for 
approximately $80 \%$ of Merkel cell carcinoma cases [4]. The remaining $20 \%$ of Merkel cell carcinoma cases lacking $\mathrm{MCPyV}$ integration are considered as a distinct tumor subset primarily caused by UV radiation [5, 6]. In line with this notion, substantial differences between the two subsets with respect to morphology [7], and immunohistochemical profiles [8] have been described. Moreover, virus-negative Merkel cell carcinomas are characterized by higher mutational burden with predominant UV signature [5, 6], and a worse outcome than their virus-positive counterparts [9].

In a previous study [10], to assess performance of a set of markers for Merkel cell carcinoma diagnosis, we characterized the expression of nine proteins by immunohistochemistry and determined the MCPyV status by quantitative PCR in a cohort of 118 patients with Merkel cell carcinoma in comparison to 85 with extra-cutaneous neuroendocrine carcinomas. To further exploit this dataset, the current study aimed to (1) compare the morphological and immunohistochemical features of MCPyV-positive and -negative Merkel cell carcinoma and (2) evaluate whether discriminative features could be used as surrogate markers for MCPyV status.

\section{Methods}

\section{Patients and samples}

Merkel cell carcinoma cases were selected from an historical/ prospective cohort of Merkel cell carcinoma patients from 6 French hospital centers. Inclusion criteria for the cohort have been described previously [11]. Briefly, patients had a diagnosis of Merkel cell carcinoma established between 1998 and 2017 (local ethics committee, Tours, France; no. ID RCB2009-A01056-51) [12]. Among the cohort, only cases with sufficient available formalin-fixed paraffin-embedded tumors for representative hematein phloxin saffron (HPS) slide staining and previously determined MCPyV status [10] were included in the present analysis.

\section{Clinical and follow-up data}

Age, sex, immunosuppression (HIV infection, organ transplant recipient, hematological malignancies), American Joint Committee on Cancer (AJCC) stage at the time of surgery [13], location of the primary tumor and follow up (recurrence free and specific survival) were collected from patient files.

\section{MCPyV status determination}

MCPyV status was determined using real time PCR with a ROC curve validated cut-off as previously described [10].
The Merkel cell carcinoma cell line WaGa (RRID: CVCL_E998) [14] was used as positive control. To note, while immunohistochemical detection of Large $\mathrm{T}$ antigen has been proposed as an efficient method to determine MCPyV status [9], our previous study comparing the performances of both procedures to distinguish Merkel cell carcinoma from other neuroendocrine carcinoma, revealed higher sensitivity (83\%) and high specificity (97\%) of MCPyV genome detection by quantitative PCR [10]. Consequently, LT staining was performed but the classification into MCPyV-positive and negative was based on quantitative PCR results.

\section{Morphologic study}

For all specimens, one representative $4 \mu \mathrm{m}$ thick, Hemateinphloxin-saffron stained section was reviewed by two pathologists (SG, TK) with blinding to diagnosis. Morphologic features were assessed by the following criteria: nuclear shape (0: regular, 1: elongated), presence of nucleoli (0: absent or inconspicuous, 1: present), cell size (0: small: $<2$ lymphocytic nuclei, 1: moderate: 2 to 3 lymphocytic nuclei, 2: large: $>3$ lymphocytic nuclei), cytoplasm volume (0: none/inconspicious, 1 : abundant), clear cytoplasm (0: no, 1: yes), rosette-like structure (0: no, 1: yes), intraepidermal component ( 0 : no, 1: yes), divergent component ( 0 : no, 1: yes) and associated intraepidermal neoplasia such as actinic keratosis or Bowen disease (0: no, 1: yes). All discordant cases were reviewed collegially.

\section{Immunohistochemistry}

We extracted data for the expression of the following markers from a previous study [10]: cytokeratin 20, thyroid transcription factor 1 (TTF- 1), atonal homolog 1 (ATOH1), neurofilament (NF), special AT-rich sequence-binding protein 2 (SATB2), paired box protein 5 (PAX5), terminal desoxynucleotidyl transferase (TdT), CD99, epithelial membrane antigen (EMA) referred as MUC1 in the previous study, and large $\mathrm{T}$ antigen (CM2B4).

In addition, we analyzed cytokeratin 7 and p53 expression as well as the staining pattern (dot, diffuse or mixed) for cytokeratins 8, 18 and 20. All antibodies are available in supplementary method Table S1. A Benchmark platform was used for staining, except for cytokeratins 8, 18 and CM2B4 stainings, which were manually performed. p53 expression was evaluated according to the Allred score whereas 0,7 and 8 are considered as abnormal expression, indicating loss of active p53 [15]. For all immunohistochemical analyses, the number of uninterpretable samples (mainly due to failure of tissue microarray inclusion) is mentioned in the corresponding figures. 


\section{Statistical analyses}

Continuous data are described by medians (Q1-Q3) and categorical data with number and percentage of interpretable cases. Associations were assessed by Mann-Whitney and two-tailed Fisher's exact tests for continuous and categorical data, respectively. $P<0.05$ was considered statistically significant. MCPyV status was determined by qPCR with a previously validated cut-off (MCPyV load >1.2 copies/cell) [10]. Categories and thresholds of immunohistochemical markers were derived from previous studies [10, 16-18]. Since no thresholds were previously determined for cytokeratins 8 , and 18 , the same categories as for cytokeratin 20 were applied. The diagnostic accuracy of immunohistochemical markers to determine MCPyV status was compared with the reference standard (quantitative PCR) by using the positive likelihood ratio as a measure of accuracy combining sensitivity and specificity. Recurrence-free survival and specific survival related to patient MCPyV status were analyzed by log-rank test and presented as Kaplan-Meier curves. Univariate and multivariate Cox proportional-hazards regression was used to identify factors associated with Merkel cell carcinoma recurrence and death, estimating hazard ratios (HRs) and 95\% confidence intervals (CIs). Specific deaths were considered events. Covariates were identified as potential prognostic confounders with $p \leq 0.25$ on Cox univariate regression analysis and then included in the multivariate Cox analysis. Statistical analysis involved use of XL-StatLife (Addinsoft, Paris, France).

\section{Results}

\section{Patient characteristics and clinical outcome}

For 101 Merkel cell carcinoma cases corresponding to 80 MCPyV-positive and 21 MCPyV-negative, sufficient material for morphologic examination allowed inclusion (Fig. 1/Flow Chart). To underline common and distinctive features of the two groups, clinical data are compared in Table 1. Virus-positive and -negative Merkel cell carcinoma did not differ with respect to age, sex, immune status, stage (American Joint Committee on Cancer), and location of the primary tumor. By contrast, Merkel cell polyomaviruspositivity was significantly associated with lower risk of recurrence (HR 0.36 CI $0.18-0.74, P=0.005$ ) and specific death (HR 0.37 CI $0.15-0.89$ ), $P=0.03$ ) on univariate analysis (Table 1/supplementary data S1) and was also statistically significant in multivariate Cox analysis (supplementary data S1). These results confirm virus-negative status as a negative prognostic marker for Merkel cell carcinoma [9].
Merkel cell carcinoma cases included in the previous study $(\mathbf{n}=118)$

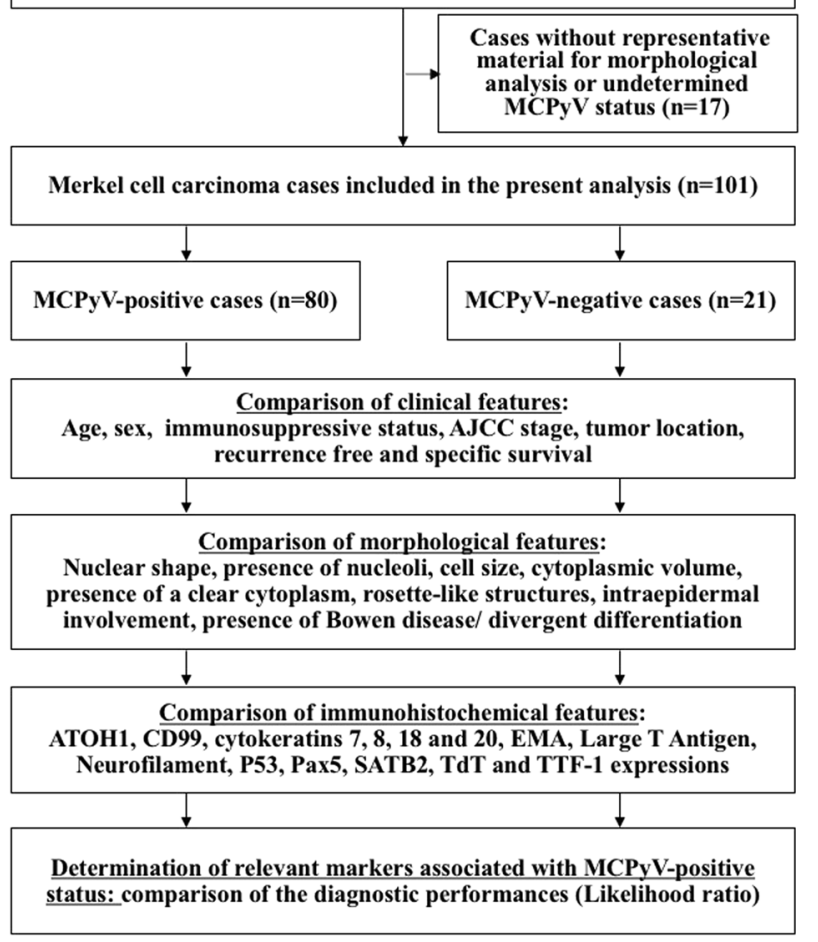

Fig. 1 Flow chart of the study

\section{MCPyV-positive and -negative cases harbor distinct morphologic features}

To evaluate the morphologic differences between the viruspositive and -negative Merkel cell carcinoma cases, assessment of nine microscopic criteria was conducted (Table 1/Fig. 2). We identified nuclear roundness to be associated $(p=0.005)$ with virus-positivity, while elongated nuclei-similar to the spindle-shape variant of small cell lung cancer-were observed more frequently in virusnegative cases. Moreover, the latter samples more frequently displayed a "large cell neuroendocrine carcinoma" phenotype, with larger cell size $(p=0.026)$, abundant cytoplasm $\left(p=4 \times 10^{-7}\right)$ and clearly visible nucleoli $(p=$ 0.002) (Table 1/Fig. 2). The combination of elongated nuclei and abundant cytoplasm was observed in 19\% $(n=$ 4) and $1 \%(n=1)$ of virus-negative and -positive cases, respectively. Furthermore, rosette-like structures (supplementary data S2) and clear cytoplasm (Fig. 2) were also associated with absence of Merkel cell polyomavirus ( $p=$ 0.02 and $2 \times 10^{-6}$ respectively). To note, $100 \%$ of cases with clear cytoplasm have also an extended cytoplasmic size. Finally, only virus-negative Merkel cell carcinoma harbored intraepidermal Merkel cell carcinoma components and displayed Bowen-associated disease or divergent differentiation (supplementary data S2). 
Table 1 Clinical, morphologic and immunohistochemical features of MCPyV-negative $(n=21)$ and -positive MCC $(n=80)$ cases. Characteristics of the two subsets were compared by non-parametric Mann Whitney and Fisher's exact tests for quantitative and qualitative data, respectively. For survival analyses, log rank test was used. Positive likelihood ratios for MCPyV positivity were assessed for markers that differed between the two groups $(p<0.05)$, by MCPyV status, by real-time PCR as the gold standard and predetermined cutoffs (underlined criteria vs rest) [4, 6, 11]

Merkel cell carcinoma cases

\begin{tabular}{|c|c|c|c|}
\hline $\begin{array}{l}\text { MCPyV-negative } \\
(n=21)\end{array}$ & $\begin{array}{l}\text { MCPyV-positive } \\
(n=80)\end{array}$ & $P$ value* & $\begin{array}{l}\text { Positive likelihood } \\
\text { ratio }(95 \% \mathrm{CI})\end{array}$ \\
\hline
\end{tabular}

\section{Clinical features}

Age, years

Median, quartiles

Missing data

Sex

\section{$\mathrm{F} / \mathrm{M}$}

Missing data

Immunosuppressive status

Yes

No

Missing data

AJCC stage

$$
\text { I }
$$

II

III

IV

Missing data

Location

Head

Trunk

Upper limb

Lower limb

Unknown primary

Missing data

Recurrence free, month

Mean survival, 95\% CI

Missing data

Specific death, month

Mean survival, $95 \%$ CI

Missing data

Morphologic features

Nuclear shape

$$
\text { Regular }
$$

Elongated

Uninterpretable cases

Nucleoli

None/inconspicuous

Present

Uninterpretable cases

Cell size

Small $(<2 \mathrm{Lc})$

Moderate (2-3 Lc)

$$
81 \text { (76-85) }
$$

$12 / 8$

1

$1(7 \%)$

$13(93 \%)$

$7(47 \%)$

$3(20 \%)$

$5(33 \%)$

0

6

$9(60 \%)$

0

0

$5(33 \%)$

$1(6.7 \%)$

6

$11(9-13)$

8

$30(5-21)$

8

$14(67 \%)$

$7(33 \%)$

0

$16(76 \%)$

5 (24\%)

0

$5(24 \%)$

$12(57 \%)$
78 (69-84)

4

0.8

$45 / 35$

0

$9(16 \%)$

46 (84\%)

25

0.45

$18(27 \%)$

22 (32\%)

$24(36 \%)$

$2(3 \%)$

14

$21(30 \%)$

$4(6 \%)$

$5(7 \%)$

28 (39\%)

$13(18 \%)$

9

0.005

66 (54-79)

13

0.027

88 (76-99)

13

0.005

1.39

74 (93\%)

$6(7 \%)$

78 (99\%)

$1(1 \%)$

17 (22\%)

$58(75 \%)$
(1.02-1.89)

\subsection{0}

(1.02-1.65)

0.026

1.20

(0.97-1.49) 
Table 1 (continued)

\begin{tabular}{|c|c|c|c|c|}
\hline & \multicolumn{2}{|c|}{ Merkel cell carcinoma cases } & \multirow[b]{2}{*}{$P$ value* } & \multirow[b]{2}{*}{$\begin{array}{l}\text { Positive likelihood } \\
\text { ratio }(95 \% \mathrm{CI})\end{array}$} \\
\hline & $\begin{array}{l}\text { MCPyV-negative } \\
(n=21)\end{array}$ & $\begin{array}{l}\text { MCPyV-positive } \\
(n=80)\end{array}$ & & \\
\hline Large (>3 Lc) & $4(19 \%)$ & $2(3 \%)$ & & \\
\hline Uninterpretable cases & 0 & 3 & & \\
\hline Cytoplasm volume & & & $4 \times 10^{-7}$ & 2.70 \\
\hline None/inconspicious & $7(33 \%)$ & $71(90 \%)$ & & $(1.47-4.96)$ \\
\hline Abundant & $14(67 \%)$ & $8(10 \%)$ & & \\
\hline Uninterpretable cases & 0 & 1 & & \\
\hline Clear cytoplasm & & & $2 \times 10^{-6}$ & 1.73 \\
\hline No & $12(57 \%)$ & $78(99 \%)$ & & $(1.19-2.50)$ \\
\hline Yes & $9(43 \%)$ & $1(1 \%)$ & & \\
\hline Uninterpretable cases & 0 & 1 & & \\
\hline Rosette-like structure & & & 0.02 & 1.35 \\
\hline No & $14(67 \%)$ & $71(90 \%)$ & & $(0.99-1.84)$ \\
\hline Yes & $7(33 \%)$ & $8(10 \%)$ & & \\
\hline Uninterpretable cases & 0 & 1 & & \\
\hline Intraepidermal component & & & 0.04 & 1.1 \\
\hline No & $19(90 \%)$ & $80(100 \%)$ & & $(0.96-1.27)$ \\
\hline Yes & $2(10 \%)$ & 0 & & \\
\hline Uninterpretable cases & 0 & 0 & & \\
\hline Divergent differentiation & & & 0.001 & 1.24 \\
\hline No & $17(81 \%)$ & $80(100 \%)$ & & $(1-1.52)$ \\
\hline Yes & $4(19 \%)$ & 0 & & \\
\hline Uninterpretable cases & 0 & 0 & & \\
\hline $\begin{array}{l}\text { Associated intraepithelial } \\
\text { neoplasia }\end{array}$ & & & 0.04 & $1.1(0.96-1.27)$ \\
\hline No & $19(90 \%)$ & $80(100 \%)$ & & \\
\hline Yes & $2(10 \%)$ & 0 & & \\
\hline Uninterpretable cases & 0 & 0 & & \\
\hline \multicolumn{5}{|l|}{ Immunohistochemical profile } \\
\hline Cytokeratin 20 & & & 0.02 & 4.5 \\
\hline Negative & $2(10 \%)$ & $6(8 \%)$ & & $(0.64-31.63)$ \\
\hline Diffuse & $2(10 \%)$ & 0 & & \\
\hline Mixed & $14(75 \%)$ & $52(68 \%)$ & & \\
\hline Dot-like pattern & $1(5 \%)$ & $18(23 \%)$ & & \\
\hline Uninterpretable cases & 2 & 4 & & \\
\hline Cytokeratin 8 & & & 0.02 & 1.73 \\
\hline Negative & 0 & 0 & & $(0.90-3.33)$ \\
\hline Diffuse & 0 & 0 & & \\
\hline Mixed & $10(63 \%)$ & $26(35 \%)$ & & \\
\hline Dot-like pattern & $6(37 \%)$ & $48(65 \%)$ & & \\
\hline Uninterpretable cases & 5 & 6 & & \\
\hline Cytokeratin 18 & & & 0.006 & 2.18 \\
\hline Negative & $1(5 \%)$ & 0 & & $(1.01-4.70)$ \\
\hline Diffuse & 0 & 0 & & \\
\hline Mixed & $13(69 \%)$ & $28(39 \%)$ & & \\
\hline
\end{tabular}


Table 1 (continued)

\begin{tabular}{|c|c|c|c|c|}
\hline & \multicolumn{2}{|c|}{ Merkel cell carcinoma cases } & \multirow[b]{2}{*}{$P$ value* } & \multirow[b]{2}{*}{$\begin{array}{l}\text { Positive likelihood } \\
\text { ratio }(95 \% \mathrm{CI})\end{array}$} \\
\hline & $\begin{array}{l}\text { MCPyV-negative } \\
(n=21)\end{array}$ & $\begin{array}{l}\text { MCPyV-positive } \\
(n=80)\end{array}$ & & \\
\hline Dot-like pattern & $5(26 \%)$ & $43(61 \%)$ & & \\
\hline Uninterpretable cases & 2 & 9 & & \\
\hline TTF-1 & & & $4 \times 10^{-6}$ & 1.92 \\
\hline Negative & $10(40 \%)$ & $72(96 \%)$ & & $(1.24-2.98)$ \\
\hline Positive & $10(50 \%)$ & $3(4 \%)$ & & \\
\hline Uninterpretable cases & 1 & 5 & & \\
\hline ATOH1 & & & 0.05 & - \\
\hline Negative & 0 & $1(1 \%)$ & & \\
\hline Low/heterogenous & $3(15 \%)$ & $29(38 \%)$ & & \\
\hline High and diffuse & $17(85 \%)$ & $46(61 \%)$ & & \\
\hline Uninterpretable cases & 1 & 4 & & \\
\hline Neurofilament & & & 0.04 & 1.49 \\
\hline Negative & $9(47 \%)$ & $17(22 \%)$ & & $(0.95-2.31))$ \\
\hline Dot-like pattern & $10(53 \%)$ & $61(78 \%)$ & & \\
\hline Uninterpretable cases & 2 & 2 & & \\
\hline SATB2 & & & 0.07 & - \\
\hline Negative & $5(25 \%)$ & $6(8 \%)$ & & \\
\hline Low/heterogenous & $6(30 \%)$ & $19(24 \%)$ & & \\
\hline High and diffuse & $9(45 \%)$ & $54(68 \%)$ & & \\
\hline Uninterpretable cases & 1 & 1 & & \\
\hline CD99 & & & 0.02 & 8.08 \\
\hline Negative & $1(5 \%)$ & $12(15 \%)$ & & $(2.16-30.21)$ \\
\hline Dot-like pattern & $2(10 \%)$ & $63(81 \%)$ & & \\
\hline Diffus & $17(85 \%)$ & $3(4 \%)$ & & \\
\hline Uninterpretable cases & 1 & 2 & & \\
\hline PAX5 & & & 0.90 & - \\
\hline Negative & $16(80 \%)$ & $57(74 \%)$ & & \\
\hline Low/heterogenous & $4(20 \%)$ & $16(21 \%)$ & & \\
\hline High and diffuse & 0 & $4(5 \%)$ & & \\
\hline Uninterpretable cases & 1 & 3 & & \\
\hline $\mathrm{TdT}$ & & & 0.34 & - \\
\hline Negative & $16(89 \%)$ & $60(76 \%)$ & & \\
\hline Positive & $2(11 \%)$ & $19(23 \%)$ & & \\
\hline Uninterpretable cases & 3 & 1 & & \\
\hline EMA & & & 0.003 & 2.70 \\
\hline Negative & $5(25 \%)$ & $22(29 \%)$ & & $(1.10-6.64)$ \\
\hline Low/heterogenous & $11(55 \%)$ & $13(17 \%)$ & & \\
\hline High and diffuse & $4(20 \%)$ & $41(54 \%)$ & & \\
\hline Uninterpretable cases & 1 & 4 & & \\
\hline Cytokeratin 7 & & & 0.006 & 1.36 \\
\hline Negative & $12(71 \%)$ & $69(96 \%)$ & & $(1-1.85)$ \\
\hline Positive & $5(29 \%)$ & $3(4 \%)$ & & \\
\hline Uninterpretable cases & 4 & 8 & & \\
\hline p53 & & & $2 \times 10^{-9}$ & 3.63 \\
\hline No expression & $7(37 \%)$ & $2(3 \%)$ & & $(1.71-7.7118)$ \\
\hline
\end{tabular}


Table 1 (continued)

\begin{tabular}{|c|c|c|c|c|}
\hline & \multicolumn{2}{|c|}{ Merkel cell carcinoma cases } & \multirow[b]{2}{*}{$P$ value* } & \multirow[b]{2}{*}{$\begin{array}{l}\text { Positive likelihood } \\
\text { ratio }(95 \% \mathrm{CI})\end{array}$} \\
\hline & $\begin{array}{l}\text { MCPyV-negative } \\
(n=21)\end{array}$ & $\begin{array}{l}\text { MCPyV-positive } \\
(n=80)\end{array}$ & & \\
\hline Heterogenous expression & $5(26 \%)$ & $63(95 \%)$ & & \\
\hline Overexpression & $7(37 \%)$ & $1(2 \%)$ & & \\
\hline Uninterpretable cases & 2 & 14 & & \\
\hline Large $\mathrm{T}$ antigen & & & $2 \times 10^{-9}$ & - \\
\hline Negative & $17(100 \%)$ & $17(23 \%)$ & & \\
\hline Positive & 0 & $58(77 \%)$ & & \\
\hline Uninterpretable cases & 4 & 5 & & \\
\hline
\end{tabular}

AJCC American Joint Committee on Cancer, ATOH1 atonal homolog 1, CI 95 confidence interval 95\%, Lc lymphocytes, MUC1 cell surfaceassociated mucin 1, PAX5 paired box protein 5, qPCR quantitative PCR, SATB2 special AT-rich sequence-binding protein 2, TdT terminal deoxynucleotidyl transferase, $T T F-1$ thyroid transcription factor 1 . *quantitative and qualitative variables were compared by Mann Whitney and Fisher's tests, for survival analyses $\log$ rank test was used $p$ values $<0.05$ and subsequent positive likelihood ratios are in bold

These results confirmed that many Merkel cell polyomavirus-positive and -negative Merkel cell carcinoma can be distinguished based on morphological criteria $[7,18,19]$ which probably reflects significant biological differences between the two groups. However, we also identified difficult-to-classify MCPyV-negative cases lacking prototypic morphologic features (supplementary data S2).

\section{MCPyV-positive and -negative cases feature distinct immunohistochemical profiles}

To determine whether also immunohistochemistry could discriminate between virus-positive and -negative Merkel cell carcinoma, we compared the two groups with respect to expression of a panel of diagnostic markers (Fig. 3/Table 1). Positivity for TTF1 and cytokeratin 7, lack of or overexpression of p53, and frequent lack of expression of neurofilament were hallmarks of the virus-negative cases (Table 1). By contrast, virus-positive cases not only featured large $\mathrm{T}$ antigen-positivity but also high EMA expression and more frequently a dot like staining pattern for the cytokeratins 8, 18 and 20, as well as for CD99. These findings demonstrate substantial variations in the immunohistochemical profiles of virus-positive and -negative Merkel cell tumors and additionally suggest a possible impact of the $\mathrm{T}$ antigens on cytoskeletal organization.

\section{CD99 dot-like pattern as a marker of MCPyV- positive Merkel cell carcinoma}

To compare the performances of all investigated markers to predict virus status, positive likelihood ratios were determined by using previously described cut-offs $[7,10,16,18]$ (Table 1). These analyses identified CD99 dot-like expression pattern as most highly associated with virus-positivity of Merkel cell carcinoma (sensitivity $=81 \%$ [95\% CI: 70-89], specificity $=90 \%$ [95\% CI: 68-99], positive predictive value $=97 \%$ [95\% CI: 89-99], negative predictive value 55\% [95\% CI: 43-66], positive likelihood ratio $=$ 8.08 [95\% CI: $2.16-30.21]$ ). In line with this, such CD99 dot-like pattern was found in $86 \%(n=49 / 57)$ of the cases which demonstrated large $\mathrm{T}$ antigen-expression in immunohistochemistry, as compared with only $35 \%(n=12 / 34)$ of large $\mathrm{T}$ antigen-negative cases (supplementary data $\mathrm{S} 3$ ). Of interest, $10 \mathrm{MCPyV}$-positive cases lacking immunohistochemical large $\mathrm{T}$ antigen expression still showed a CD99 dot-like expression pattern (positive and negative predictive values of CD99 dot pattern for MCPyV status determination in the Large T non expressing cases: 83\% [95\% CI: 56-95] and $71 \%$ [95\% CI: 56-82] respectively). These results suggest that the CD99 expression pattern might serve as an additional indicator to evaluate the Merkel cell carcinoma virus status.

\section{Discussion}

With respect to tumor cell morphology and immunophenotype, several differences between virus-positive and -negative Merkel cell carcinoma were assessed in the present study. In accordance with previous reports [7, 18], several distinctive microscopic features were observed between the two groups. Moreover, the virus-negative tumors differed from the others by a so called "aberrant" immunohistochemical profile [8] with reduced expression of the Merkel cell carcinoma marker i.e., neurofilament and a more prevalent positivity of those normally observed in extra-cutaneous neuroendocrine carcinomas such as TTF-1 and cytokeratin 7. Interestingly, dot-like expression patterns of cytokeratins and CD99 were more frequent in virus- 


\section{MCPyV-negative MCC}
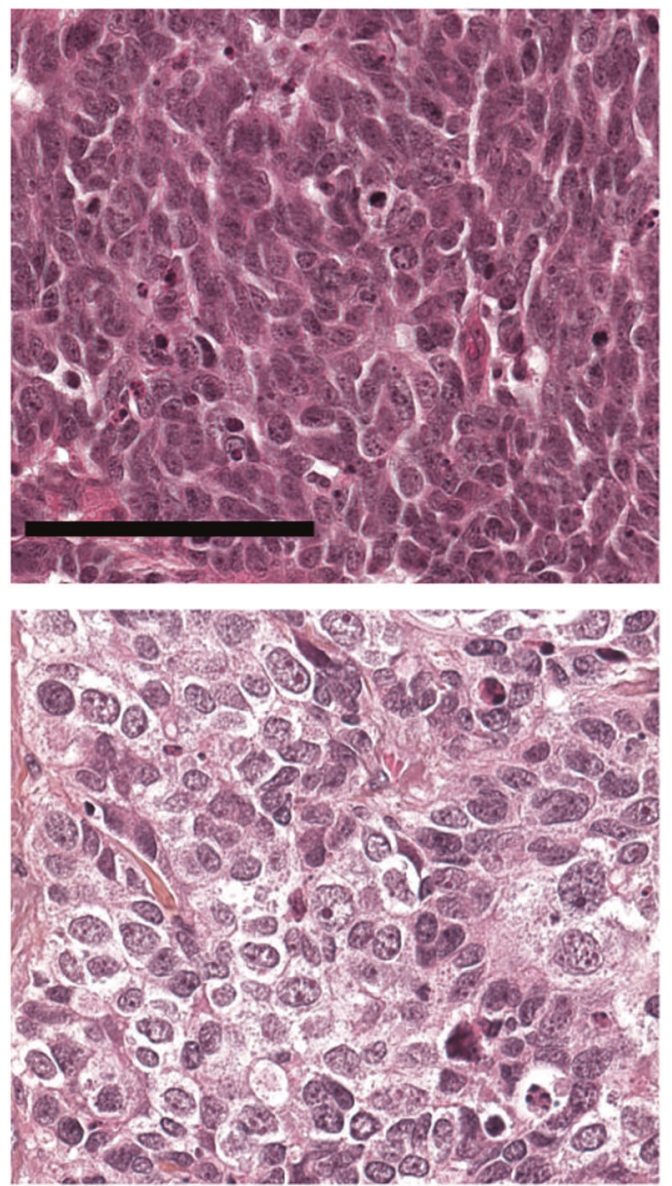

Fig. 2 Morphologic features of MCPyV-negative and -positive Merkel cell carcinoma cases $(\mathrm{bar}=100 \mu \mathrm{m})$ : on standard examination, MCPyV-negative cases are characterized by more irregular, elongated nuclei as observed in small cell lung cancer Additionally, some cases

positive cases and accordingly, CD99 expression pattern was identified as suitable additional marker for the determination of the Merkel cell polyomavirus status of Merkel cell carcinoma.

Two viral oncoproteins i.e., small $\mathrm{T}$ and Large $\mathrm{T}$ are expressed in Merkel cell carcinoma tumor cells and are considered as the main oncogenic triggers for the development of virus-positive Merkel cell carcinoma [20, 21]. In contrast, UV-induced mutations are thought to drive carcinogenesis of virus-negative Merkel cell carcinoma $[5,6,22,23]$. Targeting of the same oncogenic pathways (RB1 and p53) either by $\mathrm{T}$ antigens or somatic mutations, may account for the common neuroendocrine phenotype [24-26] observed in virus-positive and negative Merkel cell carcinomas. Nevertheless virus-negative tumors are now considered as a subset genetically distinct from the others [27] and characterized by a very high mutational burden (10 mutations per $\mathrm{Mb}$ ) while very low mutation frequencies $(0.4$ mutations per $\mathrm{Mb}$ ) were detected in Merkel cell

\section{MCPyV-positive MCC}
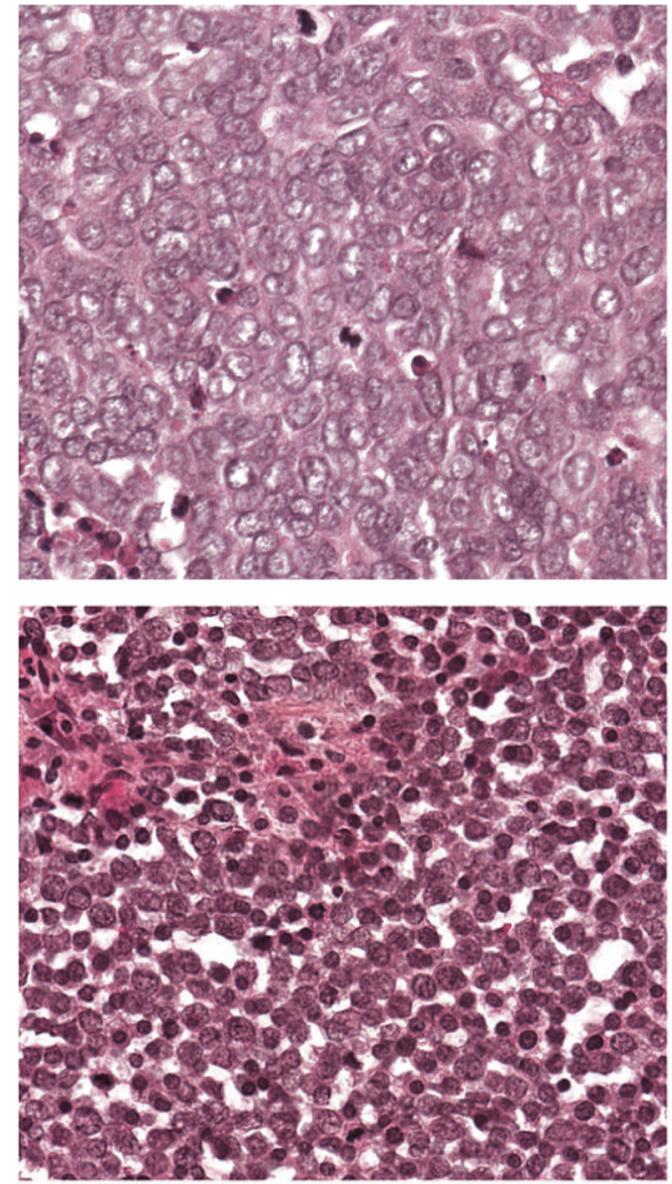

had large cell neuroendocrine carcinoma features with abundant and clear cytoplasm and predominant nuclei. By contrast, MCPyV-positive cases are composed of medium to small round tumor cells with scant cytoplasm and round nucleus. MCC: Merkel cell carcinoma

polyomavirus-positive Merkel cell carcinoma [5, 28-30]. Interestingly genomic complexity and cancer mutation burden have been demonstrated to correlate with microscopic features of tumor cells such as nuclear pleomorphism [31] and cytological atypia [32]. Indeed, in soft tissue tumors [33], "simple karyotype" neoplasias such as Ewing sarcoma with recurrent EWSR1 rearrangement display uniform, regular cytology, while "complex karyotype" sarcoma feature more pronounced cytological atypia. Similarly, the degree of differentiation was directly related to genomic alteration level in cutaneous squamous cell carcinoma [34].

In line with such observations, substantial morphologic differences were observed between virus-positive and -negative Merkel cell carcinoma. Indeed, Katano et al. [19] reported that the 6 Merkel cell polyomavirus-positive cases investigated were characterized by round and vesicular nuclei with fine granular chromatin and small nucleoli whereas, by contrast, most of the five virus-negative samples had polygonal nuclei with clear cytoplasm. Applying 


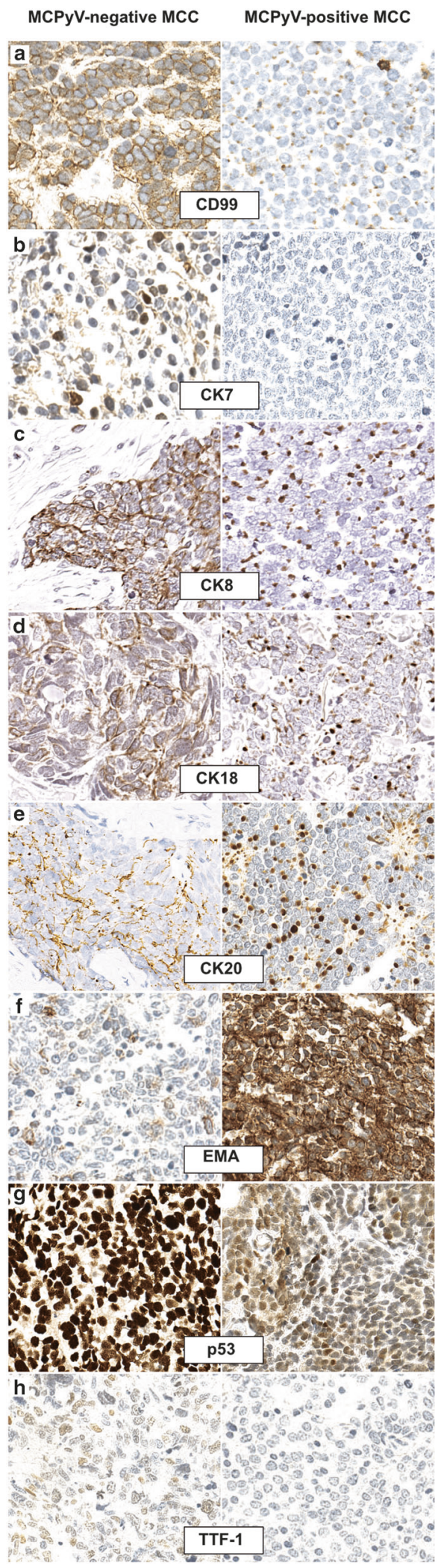

morphometry, Kuwamoto et al. [7, 18] confirmed that virusnegative cases had more irregular nuclei and more abundant cytoplasm in a set of 26 Merkel cell carcinoma cases. In our
Fig. 3 Immunophenotypes of MCPyV-negative and -positive Merkel cell carcinoma cases $(\mathrm{bar}=100 \mu \mathrm{m})$ : Immunohistochemical investigation of CD99 (a), cytokeratins 7 (b), 8 (c), 18 (d) and 20 (e), EMA (f), p53 (g) and TTF-1 (h) revealed several distinctive features between the two groups: $\mathrm{MCPyV}$-positive status was associated with cytokeratins 8, 18 and 20 and CD99 dot-like expression pattern as well as high EMA expression, whereas MCPyV-negative cases frequently displayed expression of cytokeratin 7 and TTF-1 and abnormal p53 expression. MCC: Merkel cell carcinoma

series, investigating 101 Merkel cell carcinoma cases we provide further confirmation of these microscopy-studies.

Indeed, we found MCPyV-positive cases to be characterized by uniform round-ovoid nuclei, scant cytoplasm, and frequently displaying a morphology close that of Burkitt lymphoma or Ewing sarcoma, both neoplasias either induced by virus or chromosomal translocation [33, 35]. By contrast, more heterogeneous cytological features with marked atypia were observed in virus-negative Merkel cell carcinoma which, in our view, exhibited close similarities with extracutaneous neuroendocrine carcinoma. Indeed some virusnegative cases appeared as a dense proliferation of spindle cells with elongated dark nuclei similar to the spindle shape variant of small cell lung cancer [36] while others cases, comparable to the tumor previously reported as large cell neuroendocrine carcinoma of the skin [37], feature abundant cytoplasm and prominent nuclei as shown in Fig. 2. To note, intermediary phenotypes were also observed.

While virus-positive Merkel cell carcinoma is almost exclusively located in the dermis and subcutis, involvement of the epidermis has been mostly reported for virus-negative cases. Indeed, detection of an associated intra-epidermal neoplasia as well as a divergent differentiation are predictive of MCPyV-negative status [7, 38-40]. Although, intra-epidermal spreading of Merkel cell carcinoma was only observed in two cases in our study, both of them were virus-negative suggesting that epidermotropism as an additional -although rare- characteristic of virus-negative Merkel cell carcinoma.

Whereas cytokeratin 20-positivity and TTF-1 negativity are currently used in routine practice to distinguish Merkel cell carcinomas from extra-cutaneous carcinomas [10, 41], our study confirms the prevalence of so called "aberrant" immunohistochemical profiles in virus-negative cases [8]. Indeed, these latter differed from the viral induced tumors by a more frequent negativity of the Merkel cell carcinoma markers i.e., neurofilament [8, 42, 43], and more frequent positivity of TTF-1 [44] and cytokeratin 7 [8, 45] again underlining the phenotypic similarities between virusnegative Merkel cell carcinoma and extra-cutaneous neuroendocrine carcinomas. In addition, abnormal p53 expression probably due to loss of protein function by somatic mutations was frequently observed in UV-induced tumors as previously reported [46, 47]. 
Interestingly, cytokeratins and CD99 "dot-like" patterns were associated with virus-positivity of Merkel cell carcinoma. In the interfollicular epidermis under physiological conditions, cytokeratins 8,18 and 20 expression is restricted to the Merkel cell lineage [48-50] and accordingly, frequent positivity of Merkel cell carcinoma for these cytokeratins is observed [27]. In contrast to non-neoplastic Merkel cells that show a diffuse cytokeratin expression, Merkel cell carcinoma cells often harbor cytokeratins arranged in paranuclear dots. Of note, expression of cytokeratins 8 and 18 either in a diffuse or in a dot-like pattern can also be observed in extra-cutaneous high grade neuroendocrine carcinomas [51, 52]. Interestingly such cytokeratins dot-like pattern in virus-positive Merkel cell carcinoma not only renders this feature a useful additional marker for diagnosis but also suggests a potential involvement of the $\mathrm{T}$ antigens in cytokeratin "dot like" relocation. Indeed, using a transgenic mouse model, Verhaegen et al. [53] previously obtained similar cytokeratins 8 and 20 dot-like pattern upon ectopic expression of small $\mathrm{T}$ in Merkel cells and in line with such findings, capability of $\mathrm{T}$ antigens to disrupt cellular cytoskeletal organization has previously been emphasized [54, 55]. A possible explanation for these dots is entrapment of the Golgi apparatus in the cytokeratin aggregates which might explain why not only cytokeratins but also the membrane protein $\mathrm{CD} 99$ can be found in paranuclear dots. Indeed, CD99 is a transmembrane protein involved in a broad spectrum of physiological and pathological conditions such as cell migration and intracellular trafficking [56]. In Epstein Barr virus-related Hodgkin lymphoma, direct downregulation of CD99 by the latent membrane protein 1 (LMP1) affects tumor cell differentiation and contributes to immune escape via downregulation of major histocompatibility complex class 1 [57]. Therefore CD99 sequestration in cytoplasmic "dot", might reduce the protein membrane delivery, and consequently contribute to the aggressiveness of virus positive-Merkel cell carcinoma.

While determination of the Merkel cell polyomavirus status is not yet recommended in the Merkel cell carcinoma guidelines, virus-negative cases constitute a subset of tumors phenotypically $[8,18]$ and genetically $[5,6]$ distinct from the others as described above and as underscored by the present study. In particular, increased aggressiveness and worse outcome [9] suggest a potential value of routine determination of the virus status in Merkel cell carcinoma patients. Although further confirmation in independent cohorts are needed, our results suggest that CD99 expression -with testing already available in pathology laboratories - might be used as a surrogate or associated with large $\mathrm{T}$ antigen immunohistochemistry to predict $\mathrm{MCPyV}$ status in clinical practice.

To conclude, our results confirm that MCPyV-positive and -negative Merkel cell carcinoma cases are characterized by distinct morphological and immunohistochemical features that imply a significant difference in tumor biology and behavior. Importantly, we identified a dot-like pattern in CD99 expression as a relevant marker associated with MCPyV status.

Acknowledgements Fondation ARC pour la recherche contre le cancer.

\section{Compliance with ethical standards}

Conflict of interest The authors declare that they have no conflict of interest.

Publisher's note: Springer Nature remains neutral with regard to jurisdictional claims in published maps and institutional affiliations.

\section{References}

1. Becker JC, Stang A, DeCaprio JA, et al. Merkel cell carcinoma. Nat Rev Dis Prim. 2017;3:17077.

2. Cook M, Baker K, Redman M, et al. Differential outcomes among immunosuppressed patients with merkel cell carcinoma: impact of immunosuppression type on cancer-specific and overall survival. Am J Clin Oncol. 2019;42:82-8.

3. Paulson KG, Park SY, Vandeven NA, et al. Merkel cell carcinoma: Current US incidence and projected increases based on changing demographics. J Am Acad Dermatol. 2018;78:457-63.e2.

4. Feng H, Shuda M, Chang Y, et al. Clonal integration of a polyomavirus in human Merkel cell carcinoma. Science. 2008;319: 1096-100.

5. Harms PW, Vats P, Verhaegen ME, et al. The Distinctive Mutational Spectra of Polyomavirus-Negative Merkel Cell Carcinoma. Cancer Res. 2015;75:3720-27.

6. Carter MD, Gaston D, Huang W-Y, et al. Genetic Profiles of Different Subsets of Merkel Cell Carcinoma Show Links between Combined and Pure MCPyV-negative Tumors. Hum Pathol. 2018;71:117-25.

7. Kuwamoto S, Higaki H, Kanai K, et al. Association of Merkel cell polyomavirus infection with morphologic differences in Merkel cell carcinoma. Hum Pathol. 2011;42:632-40.

8. Pasternak S, Carter MD, Ly TY, et al. Immunohistochemical profiles of different subsets of Merkel cell carcinoma. Hum Pathol. 2018;82:232-8.

9. Moshiri AS, Doumani R, Yelistratova L, et al. Polyomavirusnegative merkel cell carcinoma: a more aggressive subtype based on analysis of 282 cases using multimodal tumor virus detection. J Invest Dermatol. 2017;137:819-27.

10. Kervarrec T, Tallet A, Miquelestorena-Standley E, et al. Diagnostic accuracy of a panel of immunohistochemical and molecular markers to distinguish Merkel cell carcinoma from other neuroendocrine carcinomas. Mod Pathol. 2019;32: 499-510.

11. Kervarrec T, Gaboriaud P, Berthon P, et al. Merkel cell carcinomas infiltrated with CD33+myeloid cells and CD8+T cells are associated with improved outcome. J Am Acad Dermatol. 2018; 78:973-82.

12. Gardair C, Samimi M, Touzé A, et al. Somatostatin receptors $2 \mathrm{~A}$ and 5 are expressed in merkel cell carcinoma with no association with disease severity. Neuroendocrinology. 2015;101:223-35.

13. Harms KL, Healy MA, Nghiem P, et al. Analysis of prognostic factors from 9387 Merkel cell carcinoma cases forms the basis for 
the New 8th Edition AJCC staging system. Ann Surg Oncol. 2016;23:3564-71.

14. Schrama D, Sarosi E-M, Adam C, et al. Characterization of six Merkel cell polyomavirus-positive Merkel cell carcinoma cell lines: Integration pattern suggest that large $\mathrm{T}$ antigen truncating events occur before or during integration. Int J Cancer. 2019.

15. Watanabe G, Ishida T, Furuta A, et al. Combined Immunohistochemistry of PLK1, p21, and p53 for predicting TP53 status: an independent prognostic factor of breast cancer. Am J Surg Pathol. 2015;39:1026-34.

16. Kervarrec T, Samimi M, Gaboriaud P, et al. Detection of the Merkel cell polyomavirus in the neuroendocrine component of combined Merkel cell carcinoma. Virchows Arch Int J Pathol. 2018;472:825-37.

17. Murakami I, Takata K, Matsushita M, et al. Immunoglobulin expressions are only associated with MCPyV-positive Merkel cell carcinomas but not with MCPyV-negative ones: comparison of prognosis. Am J Surg Pathol. 2014;38:1627-35.

18. Iwasaki T, Matsushita M, Kuwamoto S, et al. Usefulness of significant morphologic characteristics in distinguishing between Merkel cell polyomavirus-positive and Merkel cell polyomavirusnegative Merkel cell carcinomas. Hum Pathol. 2013;44:1912-7.

19. Katano H, Ito H, Suzuki Y, et al. Detection of Merkel cell polyomavirus in Merkel cell carcinoma and Kaposi's sarcoma. J Med Virol. 2009;81:1951-8.

20. Shuda M, Guastafierro A, Geng X, et al. Merkel cell polyomavirus small $\mathrm{T}$ antigen induces cancer and embryonic merkel cell proliferation in a transgenic mouse model. PLoS ONE. 2015;10: e0142329.

21. Houben R, Adam C, Baeurle A, et al. An intact retinoblastoma protein-binding site in Merkel cell polyomavirus large $\mathrm{T}$ antigen is required for promoting growth of Merkel cell carcinoma cells. Int J Cancer. 2012;130:847-56.

22. Goh G, Walradt T, Markarov V, et al. Mutational landscape of MCPyV-positive and MCPyV-negative Merkel cell carcinomas with implications for immunotherapy. Oncotarget. 2016;7:3403-15.

23. Wong SQ, Waldeck K, Vergara IA, et al. UV-associated mutations underlie the etiology of MCV-negative merkel cell carcinomas. Cancer Res. 2015;75:5228-34.

24. Kaplan-Lefko PJ, Chen T-M, Ittmann MM, et al. Pathobiology of autochthonous prostate cancer in a pre-clinical transgenic mouse model. Prostate. 2003;55:219-37.

25. Syder AJ, Karam SM, Mills JC, et al. A transgenic mouse model of metastatic carcinoma involving transdifferentiation of a gastric epithelial lineage progenitor to a neuroendocrine phenotype. Proc Natl Acad Sci USA. 2004;101:4471-6.

26. González-Vela MDC, Curiel-Olmo S, Derdak S, et al. Shared oncogenic pathways implicated in both virus-positive and UVinduced merkel cell carcinomas. J Invest Dermatol. 2017;137: 197-206.

27. Busam KJ, Walsh N, Wood BA, Merkel cell carcinoma. In Elder DE, Massi D, Scolyer R, Willemze R, editors. WHO classification of skin tumours, 4th edition. Lyon: International Agency for Research on Cancer, 2018. p48-9.

28. Yarchoan M, Albacker LA, Hopkins AC, et al. PD-L1 expression and tumor mutational burden are independent biomarkers in most cancers. JCI Insight. 2019;4:126908.

29. George J, Lim JS, Jang SJ, et al. Comprehensive genomic profiles of small cell lung cancer. Nature. 2015;524:47-53.

30. Peifer M, Fernández-Cuesta L, Sos ML, et al. Integrative genome analyses identify key somatic driver mutations of small-cell lung cancer. Nat Genet. 2012;44:1104-10.

31. Cancer Genome Atlas Research Network. Comprehensive and integrated genomic characterization of adult soft tissue sarcomas. Cell. 2017;171:950-65. e28.
32. Budczies J, Bockmayr M, Denkert C, et al. Classical pathology and mutational load of breast cancer-integration of two worlds. J Pathol Clin Res. 2015;1:225-38.

33. Mariño-Enríquez A, Bovée JVMG. Molecular pathogenesis and diagnostic, prognostic and predictive molecular markers in sarcoma. Surg Pathol Clin. 2016;9:457-73.

34. Inman GJ, Wang J, Nagano A, et al. The genomic landscape of cutaneous SCC reveals drivers and a novel azathioprine associated mutational signature. Nat Commun. 2018;9:3667.

35. Rochford R, Moormann AM. Burkitt's Lymphoma. Curr Top Microbiol Immunol. 2015;390:267-85.

36. Travis W, Nicholson S, Hirsch RR et al. Small cell carcinoma. In Travis WD editor. WHO classification of tumours of lung, pleura, thymus and heart: [... reflects the views of a working group that convened for a consensus and editorial meeting at the International Agency for Research on Cancer, Lyon, April 24-26, 2014], 4th edition. Lyon: International Agency for Research on Cancer, 2015. p31-3.

37. Nagase K, Kimura H, Yonekura N, et al. Large-cell neuroendocrine carcinoma of the skin: ultrastructural and immunohistochemical findings. J Cutan Pathol. 2016;43:1067-73.

38. Martin B, Poblet E, Rios JJ, et al. Merkel cell carcinoma with divergent differentiation: histopathological and immunohistochemical study of 15 cases with PCR analysis for Merkel cell polyomavirus. Histopathology. 2013;62:711-22.

39. Busam KJ, Jungbluth AA, Rekthman N, et al. Merkel cell polyomavirus expression in merkel cell carcinomas and its absence in combined tumors and pulmonary neuroendocrine carcinomas. Am J Surg Pathol. 2009;33:1378-85.

40. Walsh NM. Primary neuroendocrine (Merkel cell) carcinoma of the skin: morphologic diversity and implications thereof. Hum Pathol. 2001;32:680-9.

41. Cheuk W, Kwan MY, Suster S, et al. Immunostaining for thyroid transcription factor 1 and cytokeratin 20 aids the distinction of small cell carcinoma from Merkel cell carcinoma, but not pulmonary from extrapulmonary small cell carcinomas. Arch Pathol Lab Med. 2001;125:228-31.

42. Miner AG, Patel RM, Wilson DA, et al. Cytokeratin 20-negative Merkel cell carcinoma is infrequently associated with the Merkel cell polyomavirus. Mod Pathol. 2015;28:498-504.

43. Stanoszek LM, Chan MP, Palanisamy N, et al. Neurofilament is superior to cytokeratin 20 in supporting cutaneous origin for neuroendocrine carcinoma. Histopathology. 2019;74:504-13.

44. Czapiewski P, Majewska H, Kutzner H, et al. TTF-1 and PAX5 are frequently expressed in combined merkel cell carcinoma. Am J Derm. 2016;38:513-6.

45. Pulitzer MP, Brannon AR, Berger MF, et al. Cutaneous squamous and neuroendocrine carcinoma: genetically and immunohistochemically different from Merkel cell carcinoma. Mod Pathol. 2015;28:1023-32.

46. Husein-ElAhmed H, Ramos-Pleguezuelos F, Ruiz-Molina I, et al. Histological Features, p53, c-Kit, and Poliomavirus Status and Impact on Survival in Merkel Cell Carcinoma Patients. Am J Derm. 2016;38:571-9.

47. Harms PW, Collie AMB, Hovelson DH, et al. Next generation sequencing of Cytokeratin 20-negative Merkel cell carcinoma reveals ultraviolet-signature mutations and recurrent TP53 and RB1 inactivation. Mod Pathol. 2016;29:240-8.

48. Van Keymeulen A, Mascre G, Youseff KK, et al. Epidermal progenitors give rise to Merkel cells during embryonic development and adult homeostasis. J Cell Biol. 2009;187: 91-100.

49. Moll I, Roessler M, Brandner JM, et al. Human Merkel cells-aspects of cell biology, distribution and functions. Eur J Cell Biol. 2005;84:259-71. 
50. Moll I, Paus R, Moll R. Merkel cells in mouse skin: intermediate filament pattern, localization, and hair cycle-dependent density. $\mathrm{J}$ Invest Dermatol. 1996;106:281-6.

51. Badzio A, Czapiewski P, Gorczyński A, et al. Prognostic value of broad-spectrum keratin clones AE1/AE3 and CAM5.2 in small cell lung cancer patients undergoing pulmonary resection. Acta Biochim Pol. 2019;66:111-4.

52. Jerome Marson V, Mazieres J, Groussard O, et al. Expression of TTF-1 and cytokeratins in primary and secondary epithelial lung tumours: correlation with histological type and grade. Histopathology. 2004;45:125-34.

53. Verhaegen ME, Mangelberger D, Harms PW, et al. Merkel cell polyomavirus small $\mathrm{T}$ antigen initiates merkel cell carcinoma-like tumor development in mice. Cancer Res. 2017;77:3151-7.
54. Knight LM, Stakaityte G, Wood JJ, et al. Merkel cell polyomavirus small $\mathrm{T}$ antigen mediates microtubule destabilization to promote cell motility and migration. J Virol. 2015;89: 35-47.

55. Kwun HJ, Wendzicki JA, Shuda Y, et al. Merkel cell polyomavirus small $\mathrm{T}$ antigen induces genome instability by $\mathrm{E} 3$ ubiquitin ligase targeting. Oncogene. 2017;36:6784-92.

56. Manara MC, Pasello M, Scotlandi K. CD99: a cell surface protein with an oncojanus role in tumors. Genes. 2018;9:E159.

57. Lee EK, Chae JH, Kang M-S. Nuclear factor- $\kappa$ B2 represses Sp1mediated transcription at the CD99 promoter. Mol Cells. 2011;32:555-60.

\section{Affiliations}

Thibault Kervarrec $\mathbb{1}^{1,2,3} \cdot$ Anne Tallet ${ }^{4}$ Elodie Miquelestorena-Standley $\mathbb{D}^{1} \cdot$ Roland Houben $\mathbb{B}^{3} \cdot$ David Schrama $^{3}$. Thilo Gambichler ${ }^{5}$ Patricia Berthon ${ }^{2}$ - Yannick Le Corre ${ }^{6}$. Ewa Hainaut-Wierzbicka ${ }^{7}$. Francois Aubin ${ }^{8}$. Guido Bens ${ }^{9}$. Flore Tabareau-Delalande ${ }^{10}$ - Nathalie Beneton ${ }^{11}$. Gaëlle Fromont ${ }^{12}$. Flavie Arbion ${ }^{12}$. Emmanuelle Leteurtre $^{13} \cdot$ Michael Herfs $^{14} \cdot$ Antoine Touzé $^{2} \cdot$ Mahtab Samimi $^{2,15} \cdot$ Serge Guyétant ${ }^{1,2}$

1 Department of Pathology, Université François Rabelais de Tours, CHU de Tours, avenue de la République, 37170 Chambray-lestours, France

2 Biologie des infections à polyomavirus team, UMR INRA ISP 1282, Université François Rabelais de Tours, 31, avenue Monge, 37200 Tours, France

3 Department of Dermatology, Venereology and Allergology, University Hospital Würzburg, Josef-Schneider-Straße 2, 97080 Würzburg, Germany

4 Platform of Somatic Tumor Molecular Genetics, Université François Rabelais de Tours, CHU de Tours, avenue de la République, 37170 Chambray-les-tours, France

5 Department of Dermatology, Venereology and Allergology, University Hospital Bochum, GudrunStraße 5, 44791 Bochum, Germany

6 Dermatology Department, LUNAM Université, CHU Angers, 4 rue Larrey, 49933 Angers, France

7 Dermatology Department, Université de Poitiers, CHU de Poitiers, 2 rue de la Milétrie, 86021 Poitiers, France
8 Dermatology Department, Université de Franche Comté, CHU Besançon, EA3181, IFR133, 2 boulevard Fleming, 25030 Besançon, France

9 Dermatology Department, CHR d'Orléans, 14 avenue de l'Hôpital, 45100 Orléans, France

10 Department of Pathology, CHR d'Orléans, 14 avenue de l'Hôpital, 45100 Orléans, France

11 Dermatology Department, CHR Le Mans, 194 avenue Rubillard, 72037 Le Mans Cedex 09, France

12 Department of Pathology, Université François Rabelais de Tours, CHU de Tours, Boulevard Tonnellé, 37044 Tours, France

13 Univ. Lille, Inserm, CHU Lille, UMR-S 1172_JPARC—JeanPierre Aubert Research Center, F-59000 Lille, France

14 Laboratory of Experimental Pathology, GIGA-Cancer, University of Liege, 4000 Liege, Belgium

15 Dermatology Department, Université Francois Rabelais, CHU de Tours, avenue de la République, 37170 Chambray-lestours, France 